\title{
Migraine and behavior in children: influence of maternal headache frequency
}

\author{
Marco A. Arruda - Marcelo E. Bigal
}

Received: 9 January 2012/ Accepted: 13 March 2012/Published online: 30 March 2012

(C) The Author(s) 2012. This article is published with open access at Springerlink.com

\begin{abstract}
We took advantage of a large population study in order to measure child behavior, as captured by the Child Behavior Checklist (CBCL) as a function of headache status in the children and their mothers. Of the target sample, consents and analyzable data were obtained from 1,856 families $(85.4 \%)$. Headache diagnoses were defined according to the second edition of the International Classification of Headache Disorders, and behavioral and emotional symptoms were assessed by the validated Brazilian version of the CBCL. We calculated the relative risk of abnormalities in the CBCL domains as a function of headache status in the children, after adjusting by a series of main effect models. Children with migraine were more likely to present abnormal scores in several of the CBCL scales, relative to children without migraine, and maternal migraine status contributed little to the model. However, when the mother had daily headaches, both children with and without migraine had similar CBCL scores. In multivariate analyses, migraine status in the children predicted CBCL scores $(p<0.01)$. Headache status and headache frequency in the mother did not predict CBCL scores in children with migraine but predicted in children without migraine $(p<0.01)$. The burden of migraine to the family
\end{abstract}

M. A. Arruda ( $\square)$

Glia Institute, Av. Braz Olaia Acosta, 727, s. 310,

CEP14026040, Ribeirão Preto, SP, Brazil

e-mail: arruda@institutoglia.com.br

M. E. Bigal

Merck Investigator Study Program and Scientific Education, Global Center for Scientific Affairs, Office of the Chief Medical Officer, Merck Inc, West Point, PA, USA

M. E. Bigal

Department of Neurology, Albert Einstein College of Medicine, Bronx, NY, USA is complex. Children with migraine are more likely to have behavioral and emotional symptoms than children without migraine. Children without migraine may be affected, in turn, by frequent headaches experienced by their mothers.

Keywords Headache - Migraine - Psychiatric comorbidity - Maternal headache $\cdot$ Childhood Epidemiology

\section{Introduction}

For several neurological disorders, early onset cases often have the highest level of biological risk and a more refractory outcomes [1]. High frequency headaches [2] and migraine [3] are common in pre-adolescent children, offering a strong opportunity for the development of studies assessing determinants of disease onset and progression.

About half of the variance in migraine prevalence is accounted for by genetic factors, leaving a strong role for environmental or non-genetic familial risk factors [4].

Epidemiological studies show that migraine aggregates within families [5-7]. The relative risk of migraine in family members of episodic migraine probands, compared with those of controls, ranges from 1.5 to 19.3 in different casuistics [8-13]. Aggregation seems to increase as a function of disease severity [11], and early onset of migraine in the proband as well as the severity of migraines is associated with higher levels of family aggregation [14]. A recent study has brought some evidence that also the headache frequency aggregates in the family [15]. Frequency of headaches in the mother predicted frequency of headaches in the children; when mother had low frequency headaches, children had increased chance to have low or intermediate headache frequency (relative risk $=1.4,1.2-1.6$ ) but not very frequent 
headaches. When mothers had headaches on more days than not (chronic daily headaches), risk of frequent headaches in the child were increased by almost 13 -fold. These findings are intriguing and may non-exclusively suggest that biological predisposition drives migraine frequency, or that shared environment exposures influence headache frequency in individuals sharing the household.

Comorbidities seem to play a role in migraine onset, progression and response to therapies, and several behavioral and emotional problems have been reported in children with migraine. Clinical [16-19] and populational studies [20,21] suggest that, relative to children without headaches, those with migraine are more likely to have somatic, anxiety, and depressive symptoms. Limited findings also suggest that pediatric migraine is associated with impaired attention span [21] and hyperactivity-impulsivity [22], but not with fully developed attention deficit hyperactivity disorder (ADHD) [22].

Nonetheless, studies accounting for the influence of maternal headache status and of headache frequency on the comorbid association are not available. Accordingly, herein, we take advantage of a large population study to measure child behavior, as captured by the Child Behavior Checklist (CBCL), as a function of headache status in the children and their mothers.

\section{Methods}

\section{Overview}

This study was conducted as part of a large ongoing population study aiming to investigate mental health and headache in children and adolescents (Attention-Brazil Project) and details of the project have been described elsewhere [23]. In brief, the project consists of two phases. In Phase 1, we piloted the methods by targeting all children from 5 to 12 years registered in the public school system of a city (Santa Cruz das Palmeiras, São Paulo, Brazil). Phase 2 (currently ongoing) draws national representation to the sample. The data reported here is not being investigated in Phase 2.

Geographic characterization and target sample

According to the demographic census, the studied region covers an area with 32,862 inhabitants (year of 2008). Of them, 30,387 (92.4\%) are in the urban area. Although the demographic census does not distinguish the age range from 5 to 12 years, there are 5,055 children from 5 to 14 years ( $15.3 \%$ of the population). Life expectancy is 73.71 years, and fecundity rate is 2.13 , rates that are similar to the Brazilian rates [24].
A total of 2,173 children were younger than 12 years and were registered in the elementary school; children registered in the middle school were not included in this study. Therefore, although all children younger than 11 years were targeted, only a subsample of those aged 11 and 12 were included.

Direct interviews were conducted for the mother or caregiver and for the teachers. Both children from urban and rural areas were assessed, as long as they were enrolled in the school system (which is mandatory). Of 2007 potential participants, consent was obtained from 1,994 (91\%) and analyzable data (complete demographics, mental health and headache information) were obtained from 1,856 children $(85.4 \%)$. The very high participation rate is explained by the active engagement of the city authorities in raising awareness about the study (see below).

Flow of the study

In February of 2009, during the planning for the 2009 school year, all teachers of the public school system were trained by one of us (MAA). They were given information about the study and educated about how to teach the parents about fulfilling the questionnaire (see below). Parents were then invited to attend a meeting at school (during the first week of the school year) and, under the supervision of the teachers which, in turn, were supervised by one of the authors of this study (MAA), fulfilled the questionnaire. Meanwhile, children remained with monitors, practicing physical activities.

\section{Questionnaires}

Parents or guardians (usually the mother) were requested to fulfill the questionnaires on demographics, mental health and headache information about the children, as well as headache information about themselves.

\section{Headache diagnosis}

The headache module of the questionnaire consisted of 14 questions, assessing the distinguishing features required for headache diagnosis of the children and their mothers according to the classification criteria of the Second Edition of the International Classification of Headache Disorders (ICHD-2) [25]. Diagnosis of chronic migraine was defined according to the 2006 appendix of the ICHD-2 [26]. The headache module is the Portuguese version of the questionnaire used in the American Migraine Studies [27] and has been validated [28].

Behavior and emotional symptoms

Two main approaches to assess behavioral symptoms at childhood exist. Categorical diagnosis that describe 
psychopathological states as distinct syndromes and dimensional approaches that view psychopathology as a deviance from normal with no clear threshold between subjects with and without a disorder [29]. The latter is the approach of the CBCL adopted by us. An advantage of this approach is to avoid stigmatization and labeling, common risks when conducting behavioral research. The CBCL was developed by Achenbach [30] for the assessment of competencies and psychopathological symptoms in children. The CBCL has been translated into over 60 languages and has been validated in numerous cross-cultural studies [29].

The validated Brazilian version of the CBCL [31] was applied. The competency score of the CBCL consists of 20 questions concerning school achievement, social, and activity scores. From these 3 scales, a total competency score is obtained. The behavior and emotional symptoms score consists of 112 questions focusing on the previous 6 months, which determine 8 symptom scales: 'Withdrawal', 'Somatic complaints', 'Anxiousness/Depression', 'Social problems', 'Thought problems', 'Attentional problems', 'Delinquent behavior', and 'Aggressive behavior'. A ninth scale focusing on 'sexual problems' was not included. Two composite scales, Internalizing and Externalizing, were determined. The internalizing scale comprises the 'Withdrawal', 'Somatic complaints' and 'Anxiousness/ Depression' scales. The externalizing scale is composed of the 'Delinquent' and 'Aggressive' behavior scales. The sum of scores of all scales defines the total problem score. The behavior-related factors differ according to age and gender. 'Clinical relevance' of behavioral and emotional problems was defined as a CBCL total problem score $\geq 70$ [30].

\section{Analyses}

Sex-specific 1-year prevalence of headache diagnoses was derived by age, race, and income (and used in the analyses, although not presented in full detail to keep the paper focused). To characterize the sample, descriptive statistics were performed. Crude and adjusted prevalence ratios were obtained using binary regression model. Prevalence ratios and $95 \%$ confidence intervals compared specific categories (e.g., age categories or race) with the reference category.

For all contrasts children without headaches of mother without headaches were specified as the reference. We first calculated the relative risk of abnormalities in the CBCL domains as a function of headache status in the children, in crude analyses. We then developed multivariate models estimating CBCL scores as a function of headache status in the mother, children, and of headache frequency in the children after adjusting for demographics, and headache symptoms (nausea, photophobia, phonophobia, severity of pain).
Investigation review board approval

This study and surveys received full approval from a Human Research Committee (School of Medicine at São José do Rio Preto Medical School, São Paulo, Brazil). Written informed consents were obtained.

\section{Results}

Table 1 displays the demographics of the participating sample and also of those without complete data. Around $52 \%$ of respondents were boys, and most were from the middle class (income class $\mathrm{C}$ ). Participation rates were very high for all the categories although decreased as a function of decreased family income.

Of the assessed children, 345 (18.6\%) had not experienced any headache in the past year, and $118(6.3 \%)$ met full criteria for migraine with and without aura. The overall prevalence of migraine was $6.4 \%$, being $6.1 \%$ in boys and $6.6 \%$ in girls (non-significant difference). Prevalence was $6.0 \%$ in white children and $7.3 \%$ in non-white (non-significant difference). Prevalence increased with age. Using the age of 5-6 as the reference $(3.2 \%)$, prevalence was numerically increased in all subsequent ages, and significantly increased at the age 7-8 $(6.2 \%, \mathrm{RR}=1.9,95 \%$

Table 1 Demographics of the sample and response rates

\begin{tabular}{|c|c|c|c|c|c|}
\hline & \multicolumn{2}{|c|}{ Respondents } & \multicolumn{2}{|c|}{ Non-respondents } & \multirow[t]{2}{*}{ Response rate $(\%)$} \\
\hline & $n$ & $\%$ & $n$ & $\%$ & \\
\hline \multicolumn{6}{|l|}{ Age } \\
\hline 5 & 90 & 4.8 & 13 & 8.6 & 87.4 \\
\hline 6 & 350 & 18.9 & 18 & 11.9 & 95.1 \\
\hline 7 & 310 & 16.7 & 39 & 25.8 & 88.8 \\
\hline 8 & 370 & 19.9 & 33 & 21.9 & 91.8 \\
\hline 9 & 465 & 25.1 & 27 & 17.9 & 94.5 \\
\hline $10+$ & 271 & 14.6 & 21 & 13.9 & 92.8 \\
\hline \multicolumn{6}{|l|}{ Gender } \\
\hline Girls & 897 & 48.3 & 65 & 43.0 & 93.2 \\
\hline Boys & 959 & 51.7 & 86 & 57.0 & 91.8 \\
\hline \multicolumn{6}{|l|}{ Race } \\
\hline White & 1,082 & 58.3 & 64 & 42.4 & 94.4 \\
\hline Non-white & 699 & 37.7 & 62 & 41.1 & 91.9 \\
\hline Not stated & 75 & 4.0 & 25 & 16.6 & 75.0 \\
\hline \multicolumn{6}{|l|}{ Income class } \\
\hline $\mathrm{A}, \mathrm{B}$ & 329 & 17.7 & 16 & 10.6 & 95.4 \\
\hline $\mathrm{C}$ & 976 & 52.6 & 56 & 37.1 & 94.6 \\
\hline $\mathrm{D}, \mathrm{E}$ & 551 & 29.7 & 79 & 52.3 & 87.5 \\
\hline Total & 1,856 & & 151 & & 92.5 \\
\hline
\end{tabular}


Table 2 Prevalence of headache and migraine by age, gender, race and income

\begin{tabular}{|c|c|c|c|c|c|c|}
\hline & \multicolumn{3}{|c|}{ No headache } & \multicolumn{3}{|c|}{$\begin{array}{l}\text { Migraine with } \\
\text { and without aura }\end{array}$} \\
\hline & $n$ & $\%$ & $\begin{array}{l}\text { Relative risk } \\
\text { (95\% } \\
\text { confidence } \\
\text { interval) }\end{array}$ & $n$ & $\%$ & $\begin{array}{l}\text { Relative risk } \\
(95 \% \\
\text { confidence } \\
\text { interval) }\end{array}$ \\
\hline \multicolumn{7}{|l|}{ Age } \\
\hline 5,6 & 109 & 24.8 & Reference & 14 & 3.2 & Reference \\
\hline 7,8 & 127 & 18.7 & $0.7(0.6-0.9)$ & 42 & 6.2 & $1.9(1.1-3.5)$ \\
\hline $9,10+$ & 109 & 14.8 & $0.6(0.5-0.8)$ & 62 & 8.4 & $2.6(1.5-4.7)$ \\
\hline \multicolumn{7}{|l|}{ Gender } \\
\hline Female & 159 & 17.7 & Reference & 55 & 6.1 & Reference \\
\hline Male & 186 & 19.4 & $1.1(0.9-1.3)$ & 63 & 6.6 & $1.1(0.7-1.5)$ \\
\hline \multicolumn{7}{|l|}{ Race } \\
\hline White & 201 & 18.6 & Reference & 65 & 6.0 & Reference \\
\hline Non-white & 126 & 18.0 & $1.0(0.8-1.2)$ & 51 & 7.3 & $1.2(0.8-1.7)$ \\
\hline Not stated & 18 & 24.0 & $1.3(0.8-2.0)$ & 2 & 2.7 & $0.4(0.1-1.8)$ \\
\hline \multicolumn{7}{|l|}{ Income class } \\
\hline A, B & 49 & 14.9 & Reference & 13 & 3.9 & Reference \\
\hline $\mathrm{C}$ & 178 & 18.2 & $1.2(0.9-1.6)$ & 66 & 6.8 & $1.7(1.0-3.1)$ \\
\hline $\mathrm{D}, \mathrm{E}$ & 118 & 21.4 & $1.4(1.1-1.9)$ & 39 & 7.1 & $1.8(1.0-3.3)$ \\
\hline Total & 345 & 18.6 & & 118 & 6.4 & \\
\hline
\end{tabular}

$\mathrm{CI}=1.1-3.5)$ and of 9 or older $(8.4 \%, \mathrm{RR}=2.6,95 \%$ $\mathrm{CI}=1.5-4.7)$ (Table 2).

In preliminary analyses, not including maternal headache status, multivariate analyses found a significant relationship between any headache $(p<0.05)$ and migraine headaches $(p<0.01)$ with internalizing problems and with total CBCL score dysfunction $(p<0.01)$. Other variables did not contribute significantly to the model.

Table 3 displays the prevalence of clinical scores in different domains of the CBCL as a function of headache status in the children and their mothers. As contrasted to controls (children without headaches of mother without headaches), children without headache of mother with migraine did not present significant difference in any CBCL domains. Comparing to controls, children with migraine of mother without headaches were more likely to have abnormal scores in the following domains of CBCL (relative risk and confidence intervals are displayed on the table only for ease of reading): somatic (20.3 vs. $3.0 \%)$, anxiety-depressive (12.6 vs. $3.4 \%)$, attention (15.9 vs. $6.1 \%)$, internalizing (49.2 vs. $17.9 \%)$ and total score $(32.5$ vs. $14.5 \%)$. Relative to controls, children with migraine of mother with migraine had significant differences in the same domains: somatic (23.8 vs. $3.0 \%$ ), anxiety-depressive

Table 3 Behavioral and emotional domains as a function of headache status in the children and their mothers

\begin{tabular}{|c|c|c|c|c|c|c|c|c|c|c|c|c|c|c|c|c|}
\hline \multirow{3}{*}{\multicolumn{2}{|c|}{ CBCL domains }} & \multicolumn{8}{|c|}{$\begin{array}{l}\text { Children } \\
\text { No headache }\end{array}$} & \multicolumn{7}{|c|}{$\begin{array}{l}\text { Children } \\
\text { Migraine }\end{array}$} \\
\hline & & \multicolumn{4}{|c|}{$\begin{array}{l}\text { Mother } \\
\text { No headache }\end{array}$} & \multicolumn{4}{|c|}{$\begin{array}{l}\text { Mother } \\
\text { Migraine }\end{array}$} & \multicolumn{4}{|c|}{$\begin{array}{l}\text { Mother } \\
\text { No headache }\end{array}$} & \multicolumn{3}{|c|}{$\begin{array}{l}\text { Mother } \\
\text { Migraine }\end{array}$} \\
\hline & & $\mathrm{n}$ & $\%$ & \multicolumn{2}{|c|}{$\mathrm{RR}(95 \% \mathrm{CI})$} & $\mathrm{n}$ & $\%$ & \multicolumn{2}{|c|}{$\mathrm{RR}(95 \% \mathrm{CI})$} & $\mathrm{n}$ & $\%$ & \multicolumn{2}{|c|}{$\mathrm{RR}(95 \% \mathrm{CI})$} & $\mathrm{n}$ & $\%$ & $\mathrm{RR}(95 \% \mathrm{CI})$ \\
\hline \multicolumn{2}{|l|}{ Withdrawn } & 19 & 6.4 & \multicolumn{2}{|c|}{ Reference } & 3 & 6.5 & \multicolumn{2}{|c|}{$1.0(0.3-3.3)$} & 22 & 8.9 & \multicolumn{2}{|c|}{$1.4(0.8-2.5)$} & 7 & 3.9 & $0.6(0.3-1.4)$ \\
\hline \multicolumn{2}{|l|}{ Somatic } & 9 & 3.0 & \multicolumn{2}{|c|}{ Reference } & 1 & 2.2 & \multicolumn{2}{|c|}{$0.7(0.1-5.5)$} & 50 & 20.3 & \multicolumn{2}{|c|}{$6.7(3.6-13.3)$} & 43 & 23.8 & $7.8(3.9-15.6)$ \\
\hline \multicolumn{2}{|c|}{ Anxiety-Depressive } & 10 & 3.4 & \multicolumn{2}{|c|}{ Reference } & 2 & 4.3 & \multicolumn{2}{|c|}{$1.3(0.3-5.7)$} & 31 & 12.6 & \multicolumn{2}{|c|}{$3.7(1.9-7.4)$} & 33 & 18.2 & $5.4(2.7-10.7)$ \\
\hline \multicolumn{2}{|l|}{ Social } & 16 & 5.4 & \multicolumn{2}{|c|}{ Reference } & 2 & 4.3 & \multicolumn{2}{|c|}{$0.8(0.2-3.4)$} & 18 & 7.3 & \multicolumn{2}{|c|}{$1.3(0.7-2.6)$} & 22 & 12.2 & $2.2(1.2-4.2)$ \\
\hline \multicolumn{2}{|l|}{ Thought } & 8 & 2.7 & \multicolumn{2}{|c|}{ Reference } & 1 & 2.2 & \multicolumn{2}{|c|}{$0.8(0.1-6.3)$} & 9 & 3.7 & \multicolumn{2}{|c|}{$1.3(0.5-3.5)$} & 7 & 3.9 & $1.4(0.5-3.9)$ \\
\hline \multicolumn{2}{|l|}{ Attention } & 18 & 6.1 & Refe & nce & 4 & 8.7 & $1.4(0.5-$ & & 39 & 15.9 & $2.6(1.5-4$ & & 34 & 18.8 & $3.1(1.8-5.3)$ \\
\hline Delinquent & & 15 & 5.1 & Refe & nce & 2 & 4.3 & $0.9(0.2-?$ & & 19 & 7.7 & $1.5(0.8-2$ & & 10 & 5.5 & $1.1(0.5-2.4)$ \\
\hline Aggressive & & 12 & 4.1 & Refe & nce & 0 & 0.0 & 0.0 & & 7 & 2.8 & $0.7(0.3-1$ & & 8 & 4.4 & $1.1(0.4-2.6)$ \\
\hline Internalizing & & 53 & 17.9 & Refe & nce & 13 & 28.3 & $1.6(0.9-2$ & & 121 & 49.2 & $2.7(2.1-3$ & & 98 & 54.1 & $3.0(2.3-4.0)$ \\
\hline Externalizing & & 47 & 15.9 & Refe & nce & 5 & 10.9 & $0.7(0.3-$ & & 40 & 16.3 & $1.0(0.7-1$ & & 33 & 18.2 & $1.1(0.8-1.7)$ \\
\hline Total & & 43 & 14.5 & Refe & nce & 7 & 15.2 & $1.0(0.5-2$ & & 80 & 32.5 & $2.2(1.6-3$ & & 60 & 33.1 & $2.3(1.6-3.2)$ \\
\hline & $\begin{array}{l}\text { Chil } \\
\text { No }\end{array}$ & $\begin{array}{l}\text { en } \\
\text { adac }\end{array}$ & & & & & & & $\begin{array}{l}\text { Chil } \\
\text { Mig }\end{array}$ & $\begin{array}{l}\text { Idren } \\
\text { raine }\end{array}$ & & & & & & \\
\hline & $\begin{array}{l}\text { Mot } \\
\text { No }\end{array}$ & $\begin{array}{l}\text { her } \\
\text { leadac }\end{array}$ & & & $\begin{array}{l}\text { Mother } \\
\text { Headac }\end{array}$ & & $15 \mathrm{da}$ & or more & $\begin{array}{l}\text { Mot } \\
\text { No }\end{array}$ & $\begin{array}{l}\text { her } \\
\text { headac }\end{array}$ & & & & $\begin{array}{l}\text { her } \\
\text { dache }\end{array}$ & on 15 & days or more \\
\hline Internalizing & 53 & 17,9 & Ref & ence & 8 & 1 & 2.3 & $1.3-4.2)$ & 121 & 49,2 & & $(2.1-3.6)$ & 21 & & 3,8 & $1.1(0.8-1.5)$ \\
\hline Externalizing & 47 & 15,9 & Ref & rence & 4 & 1,1 & 1.3 & $0.5-3.3)$ & 40 & 16 & & $(0.7-3.2)$ & 5 & & 2,8 & $0.8(0.3-1.9)$ \\
\hline Total & 43 & 14,5 & Ref & rence & 6 & 1,6 & 2.1 & $1.1-4.4)$ & 80 & 32, & & $(1.6-3.1)$ & 14 & & 5,9 & $1.1(0.7-1.7)$ \\
\hline
\end{tabular}

The values in bold are statistically significant 
(18.2 vs. $3.4 \%$ ), attention (18.8 vs. $6.1 \%$ ), internalizing (54.1 vs. $17.9 \%)$ and total score (33.1 vs. $14.5 \%)$, increased by the social domain (12.2 vs. $5.4 \%$ ) (Table 3 ).

Two contrasts are worth emphasizing from Table 3. First, children with migraine had significantly different CBCL scores relative to children without migraine and this did not vary significantly as function of headache status in the mother. However, when children had no headaches, frequency of headaches in the mother mattered. Indeed, children without headaches of mothers with frequent headaches were more likely to have abnormal scores of internalizing (42.1 vs. $17.9 \%$ ) and total score symptoms (31.6 vs. $14.5 \%$ ) (Table 3 ).

In multivariate analyses, headache status in the mother and headache frequency in the mother did not predict CBCL scores in children with migraine, but predicted in children without migraine $(p<0.01)$.

\section{Discussion}

Children with early onset migraine seem to be more likely to have behavioral displays relative to children without migraine [32]. Conflicting explanations for the association exist. While some believe it reflects shared biological predisposition (e.g., brain neurotransmitter dysfunctions would predispose to migraine and these manifestations), others believed that shared environmental exposure could explain it [32]. Finally, others believe that the comorbid conditions have a direct relationship (e.g., frequency of headaches predispose to behavioral abnormalities) [33].

Three important findings emerged from our study. First, migraine influences the CBCL scores in children, which was expected and largely confirmatory by clinical [16-19] and populational studies [20,21]. Furthermore in children with migraine, headache status or headache frequency in the mother do not influence the CBCL scores. Third and more interesting, headache frequency in the mother was associated with internalizing symptoms in children without headaches.

To the best of our knowledge, only one previous study have investigated the association of headache/migraine and behavior in children and their parents in a clinical sample of 200 children with chronic headaches [33]. The authors found a high prevalence of psychiatric disorders in children with headache and their parents, but a specific pattern in children with migraine in which a higher prevalence of psychiatric disorders in parents, co-occurrence of psychiatric comorbidity and headache familial recurrence could be observed suggesting possible mechanisms of familial co-transmission of migraine and psychiatric comorbidities.

Our findings suggest that the burden of migraine to the children is incredibly complex. First, migraine per se is associated with behavioral symptoms in this population and causality needs to be assessed in future studies. Second, we found that headache status in the mother is also of importance if the children do not have migraine (but not if they have).

Our study confirms and expands findings of another population study, where individuals with and without migraine and their partners were interviewed [34]. Of people with migraine living with a household partner, $50 \%$ believed that because of their migraine, they were more likely to argue with their partners $(50 \%)$ and children (52\%), while majority (52-73\%) reported other adverse consequences for their relationships with their partner and children, and at work. Participating partners partly confirmed these findings: $29 \%$ felt that arguments were more common because of headaches and 20-60\% reported other negative effects on relationships at home. Our study adds by directly measuring psychological symptoms in the children.

We raise one very important cautionary note: we have not assessed psychiatric status in the mother and headache in the father. Therefore, although we adjusted for income, demography and headache parameters, we have not adjusted for psychiatric maternal status. Accordingly, it may well be that psychiatric maternal status predicts proband psychiatric status, and since migraine and psychiatric disorders are comorbid, we are yet missing one piece to disentangle the mechanisms of comorbidity.

Conflict of interest Dr. Bigal is a full-time employee of Merck \& Co., Inc. The paper does not discuss medications. Dr. Arruda declares that there is no conflict of interest.

Open Access This article is distributed under the terms of the Creative Commons Attribution License which permits any use, distribution, and reproduction in any medium, provided the original author(s) and the source are credited.

\section{References}

1. Reiman EM, Chen K, Alexander GE et al (2004) Functional brain abnormalities in young adults at genetic risk for late-onset Alzheimer's dementia. Proc Natl Acad Sci USA 101(1):284-289

2. Arruda MA, Guidetti V, Galli F, Albuquerque RC, Bigal ME (2010) Frequent headaches in the preadolescent pediatric population: a population-based study. Neurology 74(11):903-908

3. Abu-Arafeh I, Razak S, Sivaraman B, Graham C (2010) Prevalence of headache and migraine in children and adolescents: a systematic review of population-based studies. Dev Med Child Neurol 52(12):1088-1097

4. Ulrich V, Gervil M, Fenger K, Olesen J, Russell MB (1999) The prevalence and characteristics of migraine in twins from the general population. Headache 39(3):173-180

5. Waters WE (1971) Migraine: intelligence, social class, and familial prevalence. Br Med J 2(5753):77-81 
6. Russell MB, Hilden J, Sorensen SA, Olesen J (1993) Familial occurrence of migraine without aura and migraine with aura. Neurology 43(7):1369-1373

7. Lemos C, Castro MJ, Barros J et al (2009) Familial clustering of migraine: further evidence from a Portuguese study. Headache 49(3):404-411

8. Russell MB, Olesen J (1996) Migrainous disorder and its relation to migraine without aura and migraine with aura. A genetic epidemiological study. Cephalalgia 16(6):431-435

9. Thomsen LL, Olesen J, Russell MB (2003) Increased risk of migraine with typical aura in probands with familial hemiplegic migraine and their relatives. Eur J Neurol 10(4):421-427

10. Nyholt DR, Dawkins JL, Brimage PJ, Goadsby PJ, Nicholson GA, Griffiths LR (1998) Evidence for an X-linked genetic component in familial typical migraine. Hum Mol Genet 7(3): 459-463

11. Stewart WF, Staffa J, Lipton RB, Ottman R (1997) Familial risk of migraine: a population-based study. Ann Neurol 41(2):166172

12. Russell MB, Olesen J (1995) Increased familial risk and evidence of genetic factor in migraine. BMJ 311(7004):541-544

13. Alonso Vilatela ME, Garcia Pedroza F, Ziegler DK, Gonzalez Mendez A (1992) Familial migraine in a Mexican population. Neuroepidemiology 11(1):46-49

14. Stewart WF, Bigal ME, Kolodner K, Dowson A, Liberman JN, Lipton RB (2006) Familial risk of migraine: variation by proband age at onset and headache severity. Neurology 66(3):344-348

15. Arruda MA, Guidetti V, Galli F, Albuquerque RC, Bigal ME (2010) Frequency of headaches in children is influenced by headache status in the mother. Headache 50(6):973-980

16. Guidetti V, Galli F, Fabrizi P et al (1998) Headache and psychiatric comorbidity: clinical aspects and outcome in an 8-year follow-up study. Cephalalgia 18(7):455-462

17. Galli F, D'Antuono G, Tarantino S et al (2007) Headache and recurrent abdominal pain: a controlled study by the means of the Child Behaviour Checklist (CBCL). Cephalalgia 27(3):211-219

18. Vannatta K, Getzoff EA, Powers SW, Noll RB, Gerhardt CA, Hershey AD (2008) Multiple perspectives on the psychological functioning of children with and without migraine. Headache 48(7):994-1004

19. Bruijn J, Locher H, Passchier J, Dijkstra N, Arts WF (2010) Psychopathology in children and adolescents with migraine in clinical studies: a systematic review. Pediatrics 126(2):323-332

20. Anttila P, Sourander A, Metsahonkala L, Aromaa M, Helenius H, Sillanpaa M (2004) Psychiatric symptoms in children with primary headache. J Am Acad Child Adolesc Psychiatry 43(4): 412-419

21. Virtanen R, Aromaa M, Koskenvuo M et al (2004) Externalizing problem behaviors and headache: a follow-up study of adolescent Finnish twins. Pediatrics 114(4):981-987

22. Arruda MA, Guidetti V, Galli F, Albuquerque RC, Bigal ME (2010) Migraine, tension-type headache, and attention-deficit/ hyperactivity disorder in childhood: a population-based study. Postgrad Med 122(5):18-26

23. Arruda MA (2009) Projeto Atenção Brasil. http://www. atencaobrasil.com.br/. Accessed 27 Jan 2012

24. IBdGeE-I (2009) Estatistica da Populacao Brasileira. http://www. ibge.gov.br/home/estatistica/populacao/estimativa2008/POP2008_ DOU.pdf. Accessed 27 Jan 2011

25. HCSotIH S (2005) The international classification of headache disorders, 2nd edn (ICHD-II). Rev Neurol (Paris) 161(6-7):689691

26. Olesen J, Bousser MG, Diener HC et al (2006) New appendix criteria open for a broader concept of chronic migraine. Cephalalgia 26(6):742-746

27. Lipton RB, Stewart WF, Simon D (1998) Medical consultation for migraine: results from the American Migraine Study. Headache 38(2):87-96

28. Goncalves DA, Bigal ME, Jales LC, Camparis CM, Speciali JG (2010) Headache and symptoms of temporomandibular disorder: an epidemiological study. Headache 50(2):231-241

29. Schmeck K, Poustka F, Dopfner M et al (2001) Discriminant validity of the child behaviour checklist CBCL-4/18 in German samples. Eur Child Adolesc Psychiatry 10(4):240-247

30. Achenbach T (1991) Manual for the CBCL/4-18 and profile. Department of Psychiatry, University of Vermont, Burlington

31. Bordin I, Mari J, Caieiro M (1995) Validation of the Brazilian version of the Child Behavior Checklist (CBCL). Rev ABPAPAL 17(2):55-66

32. Galli F, Canzano L, Scalisi TG, Guidetti V (2009) Psychiatric disorders and headache familial recurrence: a study on 200 children and their parents. J Headache Pain 10(3):187-197

33. Biederman J, Monuteaux MC, Kendrick E, Klein KL, Faraone SV (2005) The CBCL as a screen for psychiatric comorbidity in paediatric patients with ADHD. Arch Dis Child 90(10):1010-1015

34. Lipton RB, Bigal ME, Kolodner K, Stewart WF, Liberman JN, Steiner TJ (2003) The family impact of migraine: populationbased studies in the USA and UK. Cephalalgia 23(6):429-440 